\title{
Qualidade dos grãos de soja armazenados em diferentes condições
}

\author{
Ernandes R. de Alencar ${ }^{1}$, Lêda R. D. Faroni ${ }^{1}$, Adilio F. Lacerda Filho ${ }^{1}$, Luiz A. Peternelli ${ }^{2}$ \& André R. Costa $^{1}$
}

\begin{abstract}
RESUMO
Objetivou-se, com este estudo, avaliar a qualidade dos grãos de soja armazenados em diferentes condições. Grãos de soja foram colhidos com aproximadamente $18,0 \%$ b.u. de teor de água e secados até $11,2,12,8$ e 14,8\% b.u. Para que os teores de água fossem mantidos, a soja foi armazenada nas seguintes condições de temperatura e umidade relativa para $11,2 \%$ : $20{ }^{\circ} \mathrm{C}$ e $61,7 \% ; 30{ }^{\circ} \mathrm{C}$ e $67,9 \% ; 40{ }^{\circ} \mathrm{C}$ e $69,4 \%$; para $12,8 \%$ : $20{ }^{\circ} \mathrm{C}$ e $73,7 \% ; 30{ }^{\circ} \mathrm{C}$ e $76,7 \%$; $40{ }^{\circ} \mathrm{C}$ e 80,8\%; e para $14,8 \%$ : $20{ }^{\circ} \mathrm{C}$ e $82,7 \% ; 30{ }^{\circ} \mathrm{C}$ e 83,9\%; $40{ }^{\circ} \mathrm{C}$ e 85,3\%. A cada 45 dias até 180 dias de armazenamento, foram determinados teor de água, classificação dos grãos, massa específica aparente, coloração e teor de lipídios. Em geral, os grãos deterioraram ao longo do armazenamento e a perda de qualidade foi mais acentuada nos grãos armazenados com 12,8 e $14,8 \%$ a $40{ }^{\circ} \mathrm{C}$. Os grãos armazenados com $14,8 \%$ a 30 e $40{ }^{\circ} \mathrm{C}$, foram classificados como fora do padrão para comercialização após 135 e 90 dias, respectivamente. A combinação de teores de água e temperaturas mais elevados intensifica o processo de deterioração qualitativa dos grãos de soja armazenados.
\end{abstract}

Palavras-chave: deterioração qualitativa, coloração dos grãos, teor de lipídios, Glycine max (L.) Merrill

\section{Quality of soy bean grains stored under different conditions}

\begin{abstract}
This study was conducted to evaluate the quality of soy bean grains stored under different conditions. The grains were harvested with moisture content (m. c.) of about 18.0\% w.b. and dried to $11.2,12.8$ and $14.8 \%$ w.b. To maintain predetermined m.c., the grains were stored at the following combinations of temperature and relative humidity: for $11.2 \%$ : $20{ }^{\circ} \mathrm{C}$ and $61.7 \% ; 30{ }^{\circ} \mathrm{C}$ and $67.9 \% ; 40{ }^{\circ} \mathrm{C}$ and $69.4 \%$; for $12.8 \%$ : $20{ }^{\circ} \mathrm{C}$ and $73.7 \% ; 30{ }^{\circ} \mathrm{C}$ and $76.7 \% ; 40{ }^{\circ} \mathrm{C}$ and $80.8 \%$; and for $14.8 \%$ : $20{ }^{\circ} \mathrm{C}$ and $82.7 \% ; 30{ }^{\circ} \mathrm{C}$ and $83.9 \% ; 40{ }^{\circ} \mathrm{C}$ and $85.3 \%$. Grains were sampled every 45 days over 180 days in order to determine m.c., grade classification, apparent specific grain mass, grain color and oil content. In general, the grains deteriorated during the storage period but the quality loss was more accentuated when stored with m.c. of 12.8 and $14.8 \%$ at $40{ }^{\circ} \mathrm{C}$. The grains stored with m.c. of $14.8 \%$ at 30 and $40{ }^{\circ} \mathrm{C}$ did not meet commercial standards after 135 and 90 days, respectively. High m.c. and temperature during storage intensify the deteriorative processes of stored soy bean grains.
\end{abstract}

Key words: qualitative deterioration, grain color, lipid content, Glycine max (L.) Merrill

1 DEA/UFV, Av. P.H. Rolfs s/nº, CEP 36570-000, Viçosa, MG. Fone (31) 3899-1874. E-mail(s): eg4042@vicosa.ufv.br; Ifaroni@ufv.br; alacerda@ufv.br; ardcosta@yahoo.com.br

2 Departamento de Informática/UFV. Fone (31) 3899-1787. E-mail: peternelli@dpi.ufv.br 


\section{INTRODUÇÃO}

No Brasil, a safra de grãos 2007/08 foi de cerca de 145 milhões de toneladas, um recorde para a agricultura interna; desse total, foram produzidos 60 milhões de toneladas de grãos de soja, ou seja, 41,4\% da produção nacional (Brasil, 2008).

A qualidade dos grãos é um parâmetro bastante relevante para comercialização e processamento, podendo afetar o valor do produto. Apesar de toda a tecnologia disponível à agricultura brasileira, as perdas qualitativas e quantitativas, originadas durante o processo de pós-colheita, ainda não são bem controladas e, durante o armazenamento, a massa de grãos é constantemente submetida a fatores externos, os quais podem ser físicos, como temperatura e umidade; químicos, como fornecimento de oxigênio, e biológicos, como bactérias, fungos, insetos e roedores (Brooker et al., 1992). Para Villa \& Roa (1979), os parâmetros temperatura, teor de água, tempo de armazenamento e percentagem de grãos quebrados, são fatores que podem acelerar ou retardar o processo de deterioração do produto.

A predição da deterioração qualitativa em grãos, segundo Tang et al. (1999), é de suma importância, uma vez que se costuma armazenar de um ano para o outro, e o tempo de armazenamento seguro é dependente da relação quantitativa entre taxa de deterioração, qualidade e condições de armazenagem dos grãos.

O armazenamento seguro, para Bailey (1974), mantém os aspectos qualitativos e quantitativos dos grãos, proporcionando condições desfavoráveis ao desenvolvimento de insetos, roedores e microrganismos. O armazenamento de grãos em ambiente natural em regiões tropicais, de acordo com Abba \& Lovato (1999), apresenta maiores problemas em decorrência das condições de temperatura e umidade relativa, se comparado com as regiões de clima temperado ou frio. Destaca-se que esses dois parâmetros são determinantes no processo de perda de viabilidade de sementes durante o armazenamento e alterações na qualidade do produto e, consequentemente, dos subprodutos (Liu, 1997; AlYahya, 2001; Kusinska, 2001; Lacerda et al., 2003; Kong et al., 2008; Malaker et al., 2008). Além disso, os grãos e derivados armazenados em condições inadequadas estão sujeitos a rancidez hidrolítica e o resultado deste processo é manifestado pelo aumento do percentual de ácidos graxos livres, pelo aumento da sensibilidade dos ácidos graxos à oxidação e pela alteração das propriedades funcionais (Narayan et al., 1988; Anwar et al., 2007).

Outro aspecto considerado crítico e determinante durante a comercialização dos grãos, é a aparência. No que se refere à soja, alterações na coloração do produto podem ocorrer durante a etapa de armazenagem, segundo Sinclair (1995) devido, principalmente, a fatores biológicos, com destaque a presença de fungos. A descoloração de grãos de soja atribuída a fungos está relacionada à qualidade pelo U.S. Official Standards (Wilson et al., 1995) e este processo também é um indicativo de alterações físicas, químicas, presença de metabólitos ou outras características desfavoráveis (Sinclair, 1992).
Considerando que no Brasil, com altos índices pluviométricos e altas temperaturas, é permitido comercializar soja com teor de água de até $14 \%$ b.u. (Brasil, 1983), este estudo teve como objetivo avaliar as alterações qualitativas dos grãos de soja armazenados com diferentes teores de água e em variadas combinações de temperatura e umidade relativa.

\section{MATERIAL E MÉTODOS}

O estudo foi realizado no Laboratório de Pré-Processamento e Armazenamento de Produtos Agrícolas do Departamento de Engenharia Agrícola - DEA e no Laboratório de Secagem e Pigmentos Naturais do Departamento de Tecnologia de Alimentos - DTA, na Universidade Federal de Viçosa.

Utilizaram-se grãos de soja (Glycine max (L.) Merrell) originados do Distrito de Almeida Campos, Nova Ponte, MG. Os grãos, colhidos com teor de água em torno de 18\%, foram secados em secador de camada fixa com ar natural, até teores de água de 11,2, 12,8 e 14,8\% b.u.; após a secagem, os grãos foram acondicionados em recipientes de plástico de aproximadamente 3,00 L e armazenados em câmaras do tipo B.O.D. (Demanda Bioquímica de Oxigênio), nas temperaturas de 20,30 e $40{ }^{\circ} \mathrm{C}$, dispostas em sala climatizada, de tal forma que possíveis oscilações da temperatura do ar ambiente não afetassem os valores de temperatura do ar dentro das câmaras.

Calcularam-se, para garantir o mesmo teor de água dos grãos de soja durante o armazenamento em diferentes temperaturas, os valores de umidade relativa de equilíbrio para cada combinação de temperatura e teor de água (Tabela 1), utilizando-se o modelo proposto por Chung-Pfost (Eq. 1):

$$
\mathrm{UR}_{\mathrm{c}}=\exp \left[-\frac{\mathrm{A}}{\mathrm{T}+\mathrm{C}} * \exp \left(-\mathrm{B}^{*} \mathrm{U}\right)\right]
$$

em que,

$$
\begin{aligned}
& \mathrm{UR}_{\mathrm{e}} \text { - umidade relativa de equilíbrio, decimal } \\
& \mathrm{U} \text { - teor de água dos grãos, base seca decimal } \\
& \mathrm{T} \text { - temperatura, }{ }^{\circ} \mathrm{C}
\end{aligned}
$$

A, B e C são constantes do modelo para grãos de soja e correspondem a 138,$45 ; 14,967$ e 24,576 , respectivamente (Navarro \& Noyes, 2001). A umidade relativa de equilíbrio, previamente calculada para cada combinação de temperatura e teor de água, foi controlada dentro de cada B.O.D. O monitoramento e a aquisição de dados foram realizados por meio de um sistema computacional denominado 1-wire ${ }^{\mathrm{TM}}$ (Martins et al., 2004).

Realizaram-se, a cada 45 dias até 180 dias de armazena-

Tabela 1. Valores de umidade relativa de equilíbrio do ar, para as respectivas combinações de temperatura e teor de água

\begin{tabular}{cccc}
\hline \multirow{2}{*}{ Temperatura ('C) } & \multicolumn{3}{c}{ Teor de água (\%) b.u. } \\
\cline { 2 - 4 } 20 & 11,0 & 13,0 & 15,0 \\
30 & 61,0 & 72,0 & 80,0 \\
40 & 67,0 & 76,0 & 83,0 \\
\hline
\end{tabular}


mento, foram realizadas as seguintes análises: teor de água, classificação dos grãos, massa específica aparente, coloração e teor de lipídios.

\section{Teor de água}

Para determinação do teor de água se utilizou o método de estufa com circulação forçada de ar, a temperatura de $103 \pm 1^{\circ} \mathrm{C}$, durante $72 \mathrm{~h}$, em três repetições, conforme recomendações da ASAE (2000), método S352.2.

\section{Classificação dos grãos}

Os grãos foram classificados de acordo com a Portaria no 262, de 23/11/1983, do Ministério da Agricultura, Pecuária e Abastecimento (Brasil, 1983).

\section{Massa específica aparente}

A massa específica aparente (MEA) dos grãos de soja foi medida em uma balança de peso hectolítrico de $1 / 4$ de litro utilizando-se grãos limpos, ou seja, os grãos retidos na peneira de 3,00 mm de diâmetro, de acordo com a Portaria no 262, de 23/11/1983, do Ministério da Agricultura Pecuária e Abastecimento (Brasil, 1983).

\section{Coloração dos grãos}

Efetuou-se a quantificação da cor dos grãos de soja com o auxílio do colorímetro triestímulo ColorQuest ${ }^{\mathrm{TM}} \mathrm{II}$, de aceitação na indústria de alimentos. Os valores de cor usados neste aparelho são relativos aos valores absolutos de uma perfeita reflexão difusa, medida em algumas condições geométricas, definida em 1974 pela Commission Internationale d’Éclairage (C.I.E) (Minguez-Mosquera et al., 1995). Os testes foram realizados em três repetições obtendo-se, então, os valores das coordenadas L (luminosidade), a e b do sistema Hunter para avaliação da cor.

Com os valores das coordenadas L, a e b, foi possível gerar parâmetro relacionado à diferença de cor $\Delta \mathrm{E}$ (Eq. 2) (Little, 1975; Francis, 1975; Mclellan et al., 1995; Maskan, 2001).

$$
\Delta \mathrm{E}=\sqrt{(\Delta \mathrm{L})^{2}+(\Delta \mathrm{a})^{2}+(\Delta \mathrm{b})^{2}}
$$

em que:

$$
\begin{aligned}
& \Delta \mathrm{E} \text { - Diferença de cor } \\
& \mathrm{L} \text { - mensurável em termos de intensidade de bran- } \\
& \text { co a preto } \\
& \text { a - mensurável em termos de intensidade de ver- } \\
& \text { melho e verde } \\
& \text { b - mensurável em termos de intensidade de ama- } \\
& \text { relo e azul. }
\end{aligned}
$$

\section{Teor de lipídios}

A determinação do teor de lipídios (TL) dos grãos de soja, previamente moídos, foi realizada de acordo com as normas AOCS (1993), método Ac 3-44, em aparelho de soxhlet durante 6 h utilizando-se éter de petróleo como solvente.

\section{Delineamento experimental}

O experimento foi montado em delineamento inteiramente casualizado, em parcelas subdivididas, com três repetições. Os tratamentos, combinações de temperatura $\left(20\right.$, 30 e $\left.40^{\circ} \mathrm{C}\right)$ e teor de água (11,2, 12,8 e 14,8\%) foram alocados na parcela, enquanto a subparcela correspondeu ao período de armazenamento (0, 45, 90, 135, 180 dias), fazendo com que a estrutura de tratamentos correspondesse ao fatorial $3 \times 3 \times 5$; inicialmente, realizou-se a análise de variância considerando-se medidas repetidas, para determinação da melhor estrutura de co-variância residual. A escolha da melhor estrutura de co-variância foi baseada principalmente, nas estatísticas de ajuste AIC (Akaike's information criterion) e BIC (Bayesian Information Criterion).

Para as variáveis condutividade elétrica, diferença de cor e teor de lipídios e índice fotométrico de cor, utilizou-se análise de regressão e, no ajuste das regressões relativas ao tempo de armazenamento em cada tratamento, técnicas de variáveis indicadoras e polinômios ortogonais.

\section{RESULTADOS E DISCUSSÃO}

\section{Teor de água}

Na Tabela 2 se apresentam os valores de teor de água de equilíbrio dos grãos de soja armazenados durante 180 dias, em três temperaturas e umidade relativa de equilíbrio $\left(\mathrm{UR}_{\mathrm{e}}\right)$. Em geral, os teores de água dos grãos de soja permaneceram praticamente constantes, com desvio padrão máximo de 0,4 , exceto para os grãos armazenados com conteúdo de água de $14,8 \%$ a $30{ }^{\circ} \mathrm{C}$ e $83 \%$ de $\mathrm{UR}_{\mathrm{e}}$ e 12,8 e $14,8 \%$ na temperatura de $40{ }^{\circ} \mathrm{C}$ e $\mathrm{UR}_{\mathrm{e}}$ de 80 e $86 \%$, respectivamente. Atribui-se o aumento do teor de água tanto pela atividade respiratória dos grãos como da microflora a eles associada, embora a taxa respiratória dos grãos seja, geralmente, menos intensa que a dos microrganismos (Muir \& White, 2000). Ainda de acordo com esses autores, a respiração dos grãos é mais intensa a medida em que se tem teores de água elevados, embora a temperatura, a umidade relativa e o estado de con-

\begin{tabular}{|c|c|c|c|c|c|c|c|}
\hline \multirow{2}{*}{$\begin{array}{l}\text { Temp. } \\
\left({ }^{\circ} \mathrm{C}\right)\end{array}$} & \multirow{2}{*}{$\begin{array}{l}\text { URe } \\
\text { (\%) }\end{array}$} & \multicolumn{5}{|c|}{ Período de armazenamento (dias) } & \multirow{2}{*}{ Média $\pm D P^{*}$} \\
\hline & & 0 & 45 & 90 & 135 & 180 & \\
\hline \multirow{3}{*}{20} & 61,0 & 11,2 & 11,2 & 10,8 & 10,7 & 10,6 & $10,9 \pm 0,3$ \\
\hline & 72,0 & 12,8 & 12,6 & 12,8 & 13,2 & 12,9 & $12,9 \pm 0,2$ \\
\hline & 80,0 & 14,8 & 15,0 & 15,6 & 14,8 & 14,7 & $15,0 \pm 0,4$ \\
\hline \multirow{3}{*}{30} & 67,0 & 11,2 & 11,3 & 11,1 & 10,5 & 10,6 & $10,9 \pm 0,4$ \\
\hline & 76,0 & 12,8 & 12,6 & 12,8 & 12,8 & 12,8 & $12,7 \pm 0,1$ \\
\hline & 83,0 & 14,8 & 15,2 & 16,3 & 17,9 & 17,3 & $16,3 \pm 1,4$ \\
\hline \multirow{3}{*}{40} & 71,0 & 11,2 & 11,4 & 11,1 & 10,9 & 10,9 & $11,1 \pm 0,2$ \\
\hline & 80,0 & 12,8 & 13,3 & 13,5 & 15,0 & 14,8 & $13,9 \pm 0,9$ \\
\hline & 86,0 & 14,8 & 15,0 & 17,6 & 17,0 & 16,2 & $16,1 \pm 1,2$ \\
\hline
\end{tabular}
servação, também influenciem o metabolismo dos grãos; eles ressaltam, também, que a água produzida durante o processo respiratório aumenta o teor de água do produto que, por sua vez, intensifica o desenvolvimento e a taxa respiratória da microflora.

Tabela 2. Valores médios de teor de água de equilíbrio dos grãos de soja armazenados a 20,30 e $40{ }^{\circ} \mathrm{C}$, durante 180 dias

* DP - Desvio padrão 


\section{Classificação dos grãos}

Apresentam-se, na Tabela 3, os percentuais médios dos grãos de soja ardidos e avariados, valores obtidos a partir dos laudos de classificação emitidos pelo Instituto Mineiro de Agropecuária - IMA, armazenados com teores de água de $11,2,12,8$ e $14,8 \%$, nas temperaturas de 20 , 30 e $40^{\circ} \mathrm{C}$; notase que, em geral, os grãos de soja mantiveram o padrão básico, exceto os grãos armazenados com teor de água de 14,8\% e temperatura acima de $30^{\circ} \mathrm{C}$. Embora seja possível verificar um aumento do percentual de grãos ardidos e, consequentemente, do total de avariados, quando os grãos foram armazenados com teor de água de $14,8 \%$ a temperatura de $30{ }^{\circ} \mathrm{C}$ a partir de 90 dias, a soja manteve o padrão básico até 180 dias de armazenamento; todavia, os grãos armazenados com teor de água de 12,8 e 14,8\% em temperatura de $40^{\circ} \mathrm{C}$, foram considerados fora do padrão básico a partir de 135 e 90 dias, respectivamente. De acordo com a Portaria $\mathrm{n}^{\circ} 262$ do Ministério da Agricultura, Pecuária e Abastecimento - MAPA (Brasil, 1983) o limite máximo de grãos avariados de soja para o padrão básico é de $8 \%$.

Os grãos ardidos, definidos por Brasil (1983) como sendo grãos ou pedaços de grãos que se apresentam pela ação do calor e/ou umidade, visivelmente fermentados com coloração marrom ou escura na casca e interiormente, é o defeito que mais contribuiu para o aumento do total de avariados (Tabela 3). O percentual de grãos ardidos representou mais de $63 \%$ do total de avariados em todas as amostras classificadas como abaixo do padrão.

\section{Massa específica aparente}

Apresentam-se, na Figura 1, os valores de massa específica aparente dos grãos armazenados com diferentes teores de água, em três temperaturas, durante 180 dias.

Observa-se que, independentemente do teor de água, a massa específica aparente dos grãos de soja permaneceu praticamente constante na temperatura de $20^{\circ} \mathrm{C}$ (Figura 1A); resultado semelhante foi observado para temperatura de $30{ }^{\circ} \mathrm{C}$ (Figura 1B), exceto para os grãos armazenados com $12,8 \%$, a partir de 90 dias de armazenamento; na soja ar- mazenada com teor de água de $12,8 \%$ a $30^{\circ} \mathrm{C}$, constatou-se presença de grande quantidade de grãos danificados por insetos-praga da Ordem Lepdoptera, Plodia Interpunctella e Sitotroga cerealella, razão da redução da massa específica aparente. Uma provável explicação da ocorrência de insetospraga é que os grãos já vieram infestados do campo. As condições ótimas de temperatura e umidade relativa para o desenvolvimento dos insetos-praga $P$. Interpunctella e $S$. cerealella são de $30{ }^{\circ} \mathrm{C}$ e $75 \%$ (Mbata \& Osuji, 1983; Hansen et al., 2004), praticamente a mesma condição de temperatura e umidade relativa de equilíbrio para os grãos com 12,8\% b.u. (Tabela 2).

Para a temperatura de $40{ }^{\circ} \mathrm{C}$ (Figura 1C), observou-se redução na massa específica aparente dos grãos de soja armazenados com teor de água de $14,8 \%$, a partir de 45 dias de armazenamento, cujo resultado confirma o incremento da atividade metabólica dos grãos devido ao elevado teor de água (Tabela 2), na temperatura de $40^{\circ} \mathrm{C}$, motivo pelo qual se verificou desenvolvimento acelerado de fungos e, após 180 dias, detectou-se alta incidência de Aspergillus glaucus (87\%), resultando no maior percentual de grãos ardidos (Tabela 2), o que pode ter contribuído para a redução da massa específica aparente. Muir \& White (2000) afirmaram que a faixa ótima de temperatura para o desenvolvimento da maioria dos microrganismos está compreendida entre 20 e $40^{\circ} \mathrm{C}$. Christensen \& Kaufmann (1974) mencionaram que a umidade relativa e a temperatura são fatores limitantes para o desenvolvimento de fungos de armazenamento; eles afirmaram, ainda, que o valor mínimo exigido de umidade relativa para o desenvolvimento de Aspergillus glaucus no intervalo de temperatura entre 26 e $30{ }^{\circ} \mathrm{C}$ é de $73 \%$.

\section{Coloração dos grãos}

Na Figura 2 se encontram as curvas de regressão referentes à diferença de cor dos grãos com os teores de água de $11,2,12,8$ e $14,8 \%$, nas temperaturas de 20,30 e $40^{\circ} \mathrm{C}$. Verificou-se, em geral, elevação na diferença de cor dos grãos durante o armazenamento, aumento este mais acentuado a

Tabela 3. Valores médios percentuais de grãos avariados de soja armazenados nas temperaturas de 20,30 e $40{ }^{\circ} \mathrm{C}$ e teores de água de $11,2,12,8$ e $14,8 \%$ b.u. durante 180 dias

\begin{tabular}{|c|c|c|c|c|c|c|c|c|c|c|c|c|c|c|c|c|}
\hline \multirow[b]{2}{*}{$\left({ }^{\circ} \mathrm{C}\right)$} & \multirow{2}{*}{$\begin{array}{c}\text { Teor de } \\
\text { água } \\
(\%)\end{array}$} & \multicolumn{15}{|c|}{ Período de armazenamento (dias) } \\
\hline & & \multicolumn{3}{|c|}{0} & \multicolumn{3}{|c|}{45} & \multicolumn{3}{|c|}{90} & \multicolumn{3}{|c|}{135} & \multicolumn{3}{|c|}{180} \\
\hline \multirow{2}{*}{20} & 11,2 & 0,5 & 1,5 & $\mathrm{RB}$ & 0,2 & 0,9 & $\mathrm{RB}$ & 0,3 & 1,4 & $\mathrm{RB}$ & 0,3 & 1,3 & RB & 0,3 & 0,5 & $\mathrm{RB}$ \\
\hline & 14,8 & 0,3 & 1,6 & $\mathrm{RB}$ & 0,3 & 1,2 & $\mathrm{RB}$ & 0,4 & 1,2 & $\mathrm{RB}$ & 0,2 & 0,8 & $\mathrm{RB}$ & 0,4 & 0,9 & $\mathrm{RB}$ \\
\hline \multirow[b]{2}{*}{30} & 11,2 & 0,8 & 1,7 & $\mathrm{RB}$ & 0,2 & 0,9 & $\mathrm{RB}$ & 0,4 & 1,1 & $\mathrm{RB}$ & 0,2 & 0,5 & $\mathrm{RB}$ & 0,3 & 0,4 & $\mathrm{RB}$ \\
\hline & 12,8 & 0,7 & 1,1 & $\mathrm{RB}$ & 0,3 & 1,1 & $\mathrm{RB}$ & 0,3 & 1,1 & $\mathrm{RB}$ & 0,4 & 0,6 & $\mathrm{RB}$ & 0,3 & 0,4 & $\mathrm{RB}$ \\
\hline \multirow{3}{*}{40} & 11,2 & 0,2 & 1,5 & $\mathrm{RB}$ & 0,2 & 0,9 & $\mathrm{RB}$ & 0,6 & 1,8 & $\mathrm{RB}$ & 0,2 & 0,7 & $\mathrm{RB}$ & 0,5 & 0,8 & $\mathrm{RB}$ \\
\hline & 12,8 & 0,5 & 1,2 & $\mathrm{RB}$ & 0,3 & 1,1 & $\mathrm{RB}$ & 0,5 & 0,9 & $\mathrm{RB}$ & 5,5 & 8,11 & FRB & 5,6 & 8,41 & FRB \\
\hline & 14,8 & 0,8 & 1,3 & $\mathrm{RB}$ & 0,4 & 1,4 & $\mathrm{RB}$ & 5,8 & 8,61 & FRB & 8,8 & 11,71 & FRB & 9,1 & 14,31 & FRB \\
\hline
\end{tabular}

ARD - Valores médios percentuais de grãos ardidos; AVD - Valores médios percentuais de grãos avariados; CLS - Classificação dos grãos de soja; RB - Percentual de grãos avariados dentro do limite da referência básica FRB - Percentual de grãos avariados acima do limite da referência básica.

${ }_{1}^{1}$ Produto classificado como Fora da Referência Básica para comercialização, por exceder o limite máximo de grãos avariados (8\%) estabelecido pela Portaria n 262 , de 23 de Novembro de 1983 , do Ministério da Agricultura, Pecuária e Abastecimento (MAPA) 


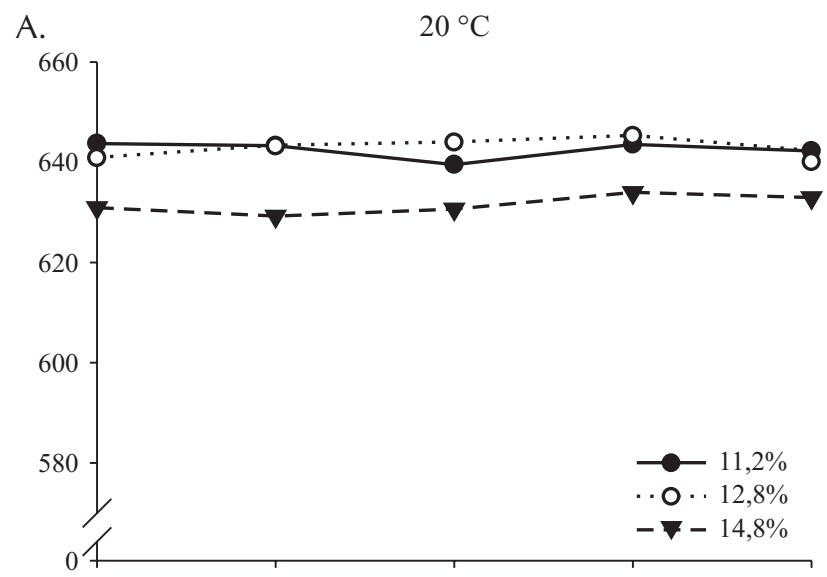

A.
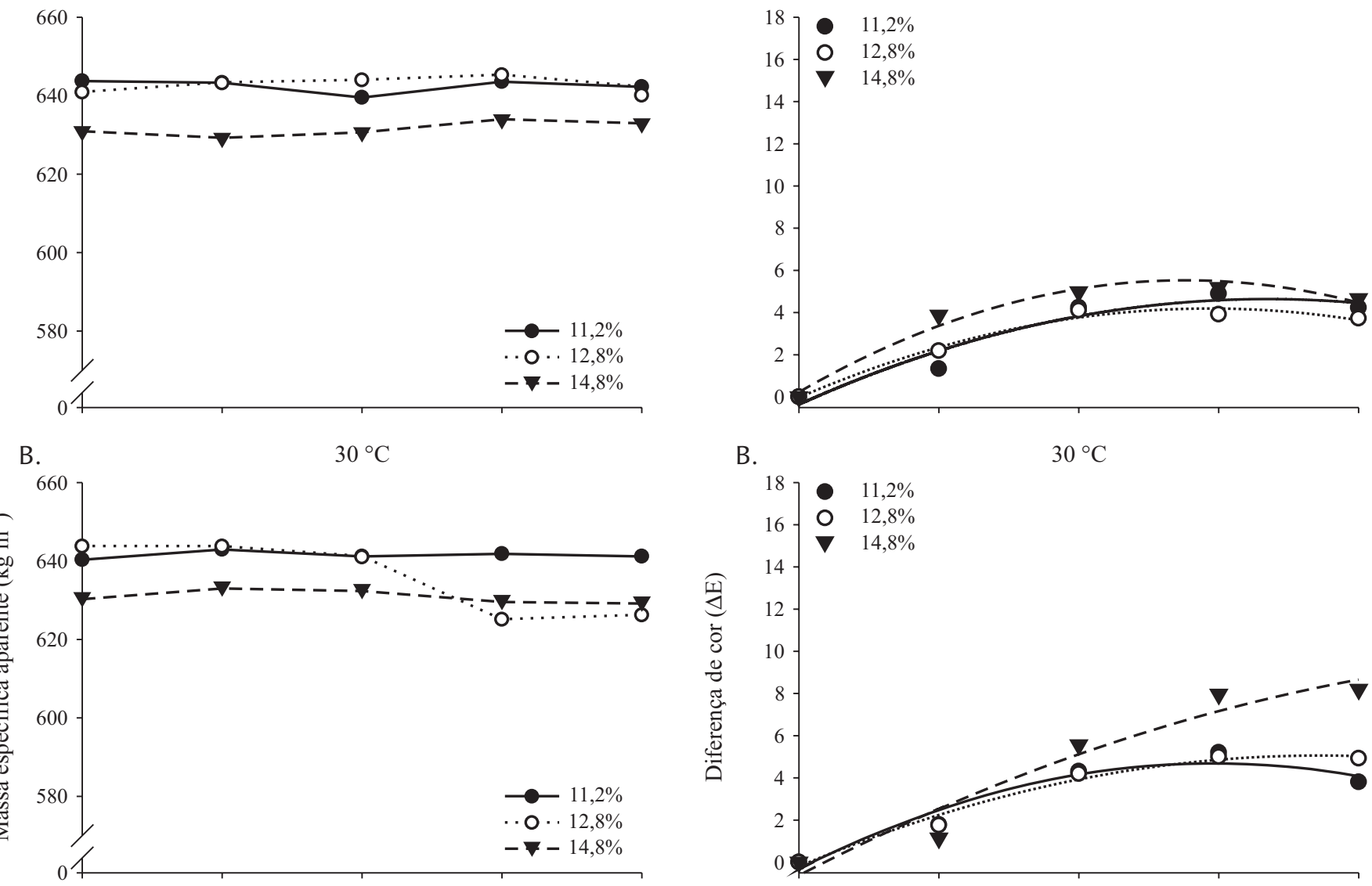

C.

$40{ }^{\circ} \mathrm{C}$

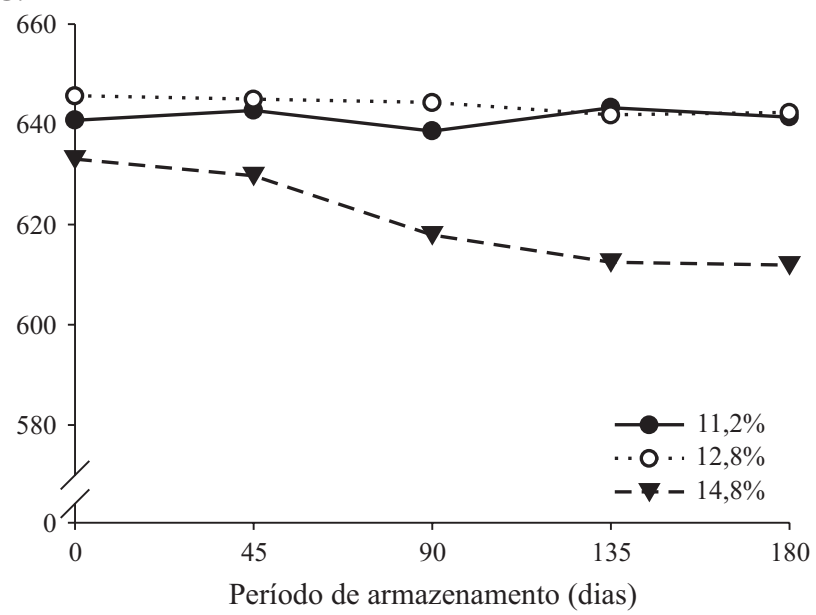

Figura 1. Valores médios de massa específica aparente dos grãos de soja armazenados com teores de água de 11,2 (A), 12,8 (B) e 14,8\% b.u. (C) nas temperaturas de 20,30 e $40{ }^{\circ} \mathrm{C}$

medida em que se elevou o teor de água e a temperatura dos grãos. As alterações observadas na coloração dos grãos de soja estão associadas ao escurecimento do produto e confirmam o desenvolvimento de fungos e, conseqüentemente, a elevação do percentual de ardidos, conforme os resultados apresentados na Tabela 3.

Hou \& Chang (2004) obtiveram resultados ao avaliarem as alterações na coloração e na composição química da soja e qualidade do tofu em diferentes condições de armazena-

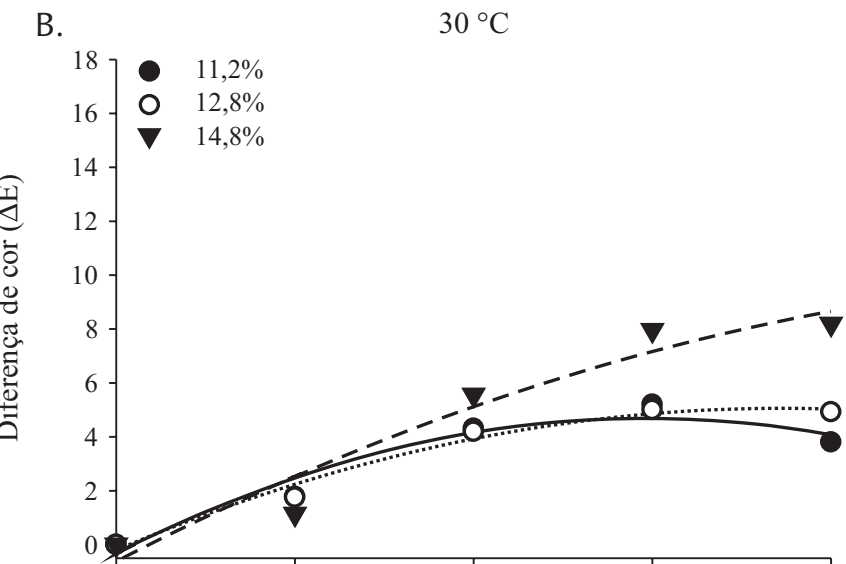

C.

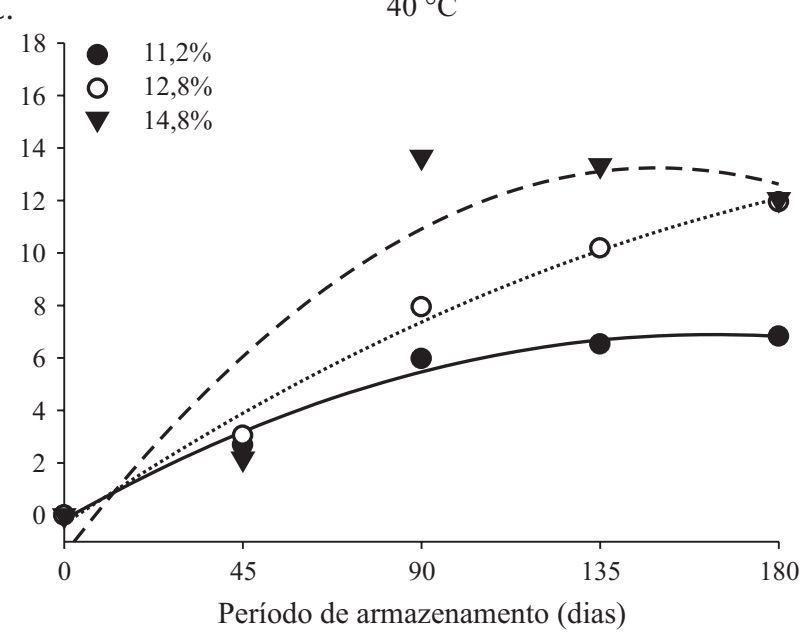

Figura 2. Curvas de regressão de diferença de cor dos grãos de soja armazenados com teores de água de 11,2 (A), 12,8 (B) e 14,8\% b.u. (C) nas temperaturas de 20,30 e $40{ }^{\circ} \mathrm{C}$

mento e observaram escurecimento dos grãos de soja somente quando armazenados a $30{ }^{\circ} \mathrm{C}$ e $84 \%$ de umidade relativa. O escurecimento da soja, segundo Saio et al. (1980), é um importante indicador de deterioração qualitativa durante o armazenamento. A variação na coloração, para Liu (1997), caracteriza o envelhecimento de sementes e está associada a outras alterações qualitativas, tais como redução do percentual de germinação.

Na Tabela 4 se apresentam as equações de regressão ajus- 
Tabela 4. Equações de regressão ajustadas para diferença de cor dos grãos de soja com teores de água de $11,2,12,8$ e $14,8 \%$ b.u. a 20 , 30 e $40{ }^{\circ} \mathrm{C}$ ao longo do período de armazenamento $(X)$, e respectivos coeficientes de determinação

\begin{tabular}{|c|c|c|c|c|c|c|c|}
\hline Temp. ( $\left.{ }^{\circ} \mathrm{C}\right)$ & Teor de água (\%) & Equações ajustadas & $\mathrm{GL}_{\text {erro }}$ & $\mathbf{R}^{2}$ & IC (95\%) & $F$ & Probabilidade \\
\hline \multirow{3}{*}{20} & 11,2 & $\hat{y}=-0,358+0,0663 x-0,0002 x^{2}$ & 12 & 0,91 & $1,82-4,04$ & 60,85 & $<0,0001$ \\
\hline & 12,8 & $\hat{y}=-0,031+0,0639 x-0,0002 x^{2}$ & 12 & 0,78 & $1,79-3,77$ & 22,36 & 0,0001 \\
\hline & 14,8 & $\hat{y}=0,227+0,0852 X-0,0003 X^{2}$ & 12 & 0,78 & $2,50-4,98$ & 20,93 & 0,0001 \\
\hline \multirow{3}{*}{30} & 11,2 & $\hat{y}=-0,329+0,0753 X-0,0003 X^{2}$ & 12 & 0,86 & $1,89-4,15$ & 36,30 & $<0,0001$ \\
\hline & 12,8 & $\hat{y}=-0,202+0,0627 X-0,0002 X^{2}$ & 12 & 0,91 & $1,99-4,35$ & 58,21 & $<0,0001$ \\
\hline & 14,8 & $\hat{y}=-0,619+0,0759 x-0,0001 X^{2}$ & 12 & 0,92 & $2,59-6,55$ & 65,70 & $<0,0001$ \\
\hline \multirow{3}{*}{40} & 11,2 & $\hat{y}=-0,169+0,0864 X-0,0003 X^{2}$ & 12 & 0,95 & $2,84-5,94$ & 104,23 & $<0,0001$ \\
\hline & 12,8 & $\hat{y}=-0,330+0,1020 x-0,0002 X^{2}$ & 12 & 0,96 & $4,03-9,21$ & 138,78 & $<0,0001$ \\
\hline & 14,8 & $\hat{y}=-1,488+0,1972 X-0,0007 X^{2}$ & 12 & 0,82 & $4,79-11,69$ & 27,62 & $<0,0001$ \\
\hline
\end{tabular}

tadas e seus respectivos coeficientes de determinação, que relacionam a diferença de cor dos grãos de soja e o período de armazenamento, em três teores de água, para cada temperatura de armazenamento.

\section{Teor de lipídios}

Pelo teste $\mathrm{F}$ a $5 \%$ de profundidade, os resultados da análise de variância indicaram variação significativa do teor de lipídios dos grãos de soja devido à interação teor de água, temperatura e período de armazenamento.

O efeito do período de armazenamento sobre o teor de lipídios dos grãos de soja (expresso em base seca) em três teores de água e três temperaturas, é mostrado na Figura 3; em geral, o teor de lipídios dos grãos não alterou, ao longo do período de armazenamento, exceto para os grãos armazenados com teor de água de $14,8 \%$, as temperaturas de 30 e $40{ }^{\circ} \mathrm{C}$ (Figuras 3B e C).

Apresentam-se, na Tabela 5, as equações de regressão ajustadas e seus respectivos coeficientes de determinação, que relacionam o teor de lipídios dos grãos de soja e o período de armazenamento. A diminuição do teor de lipídios somente foi significativa quando os grãos foram armazenados com teor de água de $14,8 \%$ nas temperaturas de 30 e $40^{\circ} \mathrm{C}$.

Hou \& Chang (2004) ao analisarem a composição química dos grãos de soja armazenados em diferentes condições, verificaram aumento do teor de lipídios quando os grãos foram armazenados a $30^{\circ} \mathrm{C}$ e $84 \%$ de umidade relativa; todavia, os autores não souberam explicar este aumento. (Rupollo et al., 2004) encontraram decréscimo significativo do teor de lipídios em grãos de aveia, principalmente nos três primeiros meses de armazenamento, e afirmaram que a degradação de lipídios ocorre durante o armazenamento em virtude de processos bioquímicos, como a respiração, ou processos de oxidação. Resultados semelhantes já haviam sido observados por Molteberg et al. (1995) quando notaram decréscimo do teor de lipídios em aveia armazenada em diferentes condições. Zhou et al. (2002) mostraram a influência da temperatura e do período de armazenamento no teor de lipídios em grãos de arroz; enquanto em grãos armazenados a $35{ }^{\circ} \mathrm{C}$ ocorre decréscimo significativo do teor de lipídios, o mesmo não acontece em grãos a $5{ }^{\circ} \mathrm{C}$ após 12 meses.

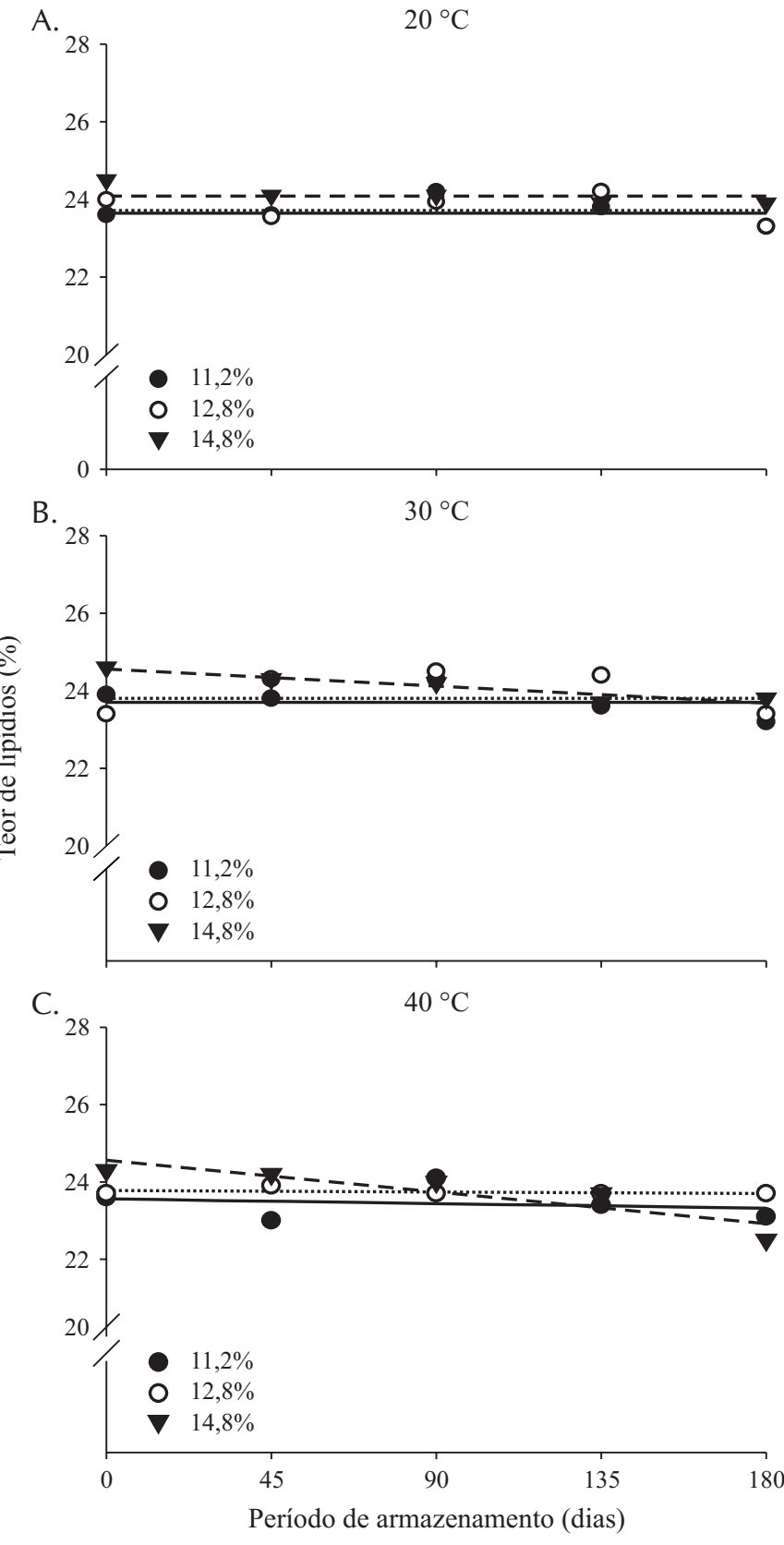

Figura 3. Curvas de regressão de teor de lipídios (em base seca) dos grãos de soja armazenados com teores de água de $11,2,12,8$ e $14,8 \%$ b.u. nas temperaturas de 20,30 e $40^{\circ} \mathrm{C}$ 
Tabela 5. Equações de regressão ajustadas para teor de lipídios dos grãos de soja com teores de água de $11,2,12,8$ e $14,8 \%$ b.u. a 20,30 e $40{ }^{\circ} \mathrm{C}$ ao longo do período de armazenamento $(X)$, e respectivos coeficientes de determinação

\begin{tabular}{|c|c|c|c|c|c|c|c|}
\hline Temp. ( $\left.{ }^{\circ} \mathrm{C}\right)$ & Teor de água (\%) & Equações ajustadas & $\mathbf{g l}_{\text {erro }}$ & $\mathrm{R}^{2}$ & IC(95\%) & $\bar{F}$ & Prob. \\
\hline \multirow[b]{2}{*}{20} & 11,2 & $\hat{y}=23,6$ & 13 & & $23,50-23,95$ & 0,23 & 0,6364 \\
\hline & 12,8 & $\hat{y}=23,7$ & 13 & & $23,82-24,30$ & 3,36 & 0,0897 \\
\hline \multirow{3}{*}{30} & 11,2 & $y=23,7$ & 13 & & $23,57-24,02$ & 2,26 & 0,1571 \\
\hline & 12,8 & $\hat{y}=23,8$ & 13 & & $23,58-24,33$ & 0,27 & 0,6105 \\
\hline & 14,8 & $\hat{y}=24,6-0,0049 x$ & 13 & 0,56 & $23,83-24,40$ & 16,27 & 0,0014 \\
\hline \multirow[t]{2}{*}{40} & 12,8 & $\hat{y}=23,7$ & 13 & & $23,60-23,94$ & 0,14 & 0,7117 \\
\hline & 14,8 & $\hat{y}=24,6-0,0091 x$ & 13 & 0,76 & $23,35-24,12$ & 40,64 & $<0,0001$ \\
\hline
\end{tabular}

\section{CONCLUSÕES}

1. A combinação de teores de água e temperaturas mais elevados intensifica o processo de deterioração dos grãos de soja armazenados.

2. Para comercialização de soja como dentro da referência básica, é possível armazenar, durante 180 dias, grãos com teor de água de até $14,8 \%$ nas temperaturas de 20 e $30{ }^{\circ} \mathrm{C}$.

3. Na temperatura de $40{ }^{\circ} \mathrm{C}$ somente os grãos com teor de água de até $11,0 \%$ podem ser armazenados durante 180 dias.

\section{LITERATURA CITADA}

Abba, E. J.; Lovato, A. Effect of seed storage temperature and relative humidity on maize (Zea mays L.) seed viability and vigour. Seed Science and Technology, v.27, p.101-114, 1999.

Al-Yahya, S. A. Effect of storage conditions on germination in wheat. Journal Agronomy \& Crop Science, v.186, p.273-279, 2001.

Anwar, F.; Chatha, S. A. S.; Hussain, A. I. Assessment of oxidative deterioration of soybean oil at ambient and sunlight storage. Grasas y Aceites, v.58, n.4, p.390-395, 2007.

AOCS - American Oil Chemists' Society. Official methods and recommended practices. 4.ed. Champaign: AOCS., 1993. 2v.

ASAE - American Society of Agricultural Engineers. Moisture measurement - unground grain and seeds. In: Standards, 2000. St. Joseph: ASAE, 2000. 563p.

Bailey, J. E. Whole grain storage. In: Christensen, C. M. (ed.) Storage of cereal grains and their products. St. Paul: AACC., 1974. p.333-360.

Brasil. Ministério da Agricultura, Pecuária e Abastecimento. Portaria nº 262 de 23.11.1983, D.O.U. 25.11.1983, Brasília/DF.

Brasil. Ministério da Agricultura, Pecuária e Abastecimento. Companhia Nacional de Abastecimento. Acompanhamento da safra brasileira. http://www.conab.gov.br/conabweb/download/safra/ 2graos_08.09.pdf. 20 Nov. 2008.

Brooker, D. B.; Bakker-Arkema, F.W.; Hall, C.W. Drying and storage of grains and oilseeds. New York: Van Nostrand Reinhold, 1992. 450p.
Christensen, C. M.; Kaufmann, H. H. Microflora. In: Christensen, C. M. (ed.) Storage of cereal grains and their products. St. Paul: AACC., 1974. p.158-192.

Francis, F. J. The origin of $\tan ^{-1}$ a/b. Journal of Food Science, v.40, p.412, 1975.

Hansen, L. S.; Skovgard, H.; Hell, K. Life table study of Sitotroga cerealella (Lepidoptera: Gelichiidae), a strain from West Africa. Journal of Economic Entomology, v.97, n.4, p.1484-1490, 2004.

Hou, H. J.; Chang, K. C. Storage conditions affect soybean color, chemical composition and tofu qualities. Journal of Food Processing and Preservation, v.28, p.473-488, 2004.

Kong, F.; Chang, S. K. C.; Liu, Z.; Wilson, L. A. Changes of soybean quality during storage as related to soymilk and tofu making. Journal of Food Science, v.73, n.3, p.134-144, 2008.

Kusinska, E. Effect of the triticale grain moisture content on the spontaneous heating of grain and on the pressure against the silo wall. Institute of Agrophysics, v.15, p.247-254, 2001.

Lacerda, A. D. S.; Lazarini, E.; Sá, M. E.; Valério Filho, W. V. Armazenamento de sementes de soja dessecadas e avaliação da qualidade fisiológica, bioquímica e sanitária. Revista Brasileira de Sementes, v.25, n.2, p.97-105, 2003.

Little, A. Off on a tangent. Journal of Food Science, v.40, p.410-411, 1975.

Liu, K. Soybeans: chemistry, technology and utilization. New York: Chapman \& Hall, 1997. 532p.

Malaker, P. K.; Mian, I. H.; Bhuiyan, K. A.; Akanda, A. M.; Reza, M. M. A. Effect of storage containers and time on seed quality of wheat. Bangladesh Journal of Agricultural Research, v.33, n.3, p.469-477, 2008.

Martins, J. H.; Monteiro, P. M. B.; Mota, A. M. N.; Fonseca, J. A.G. The 1-wire ${ }^{\mathrm{TM}}$ system - an application for agricultural processes. In: Portuguese Conference on Automatic Control. 6th, 2004, Faro, Portugal. Proceedings... Faro: Controlo, 2004. p.602-607.

Maskan, M. Kinetics of colour change of kiwifruits during hot air and microwave drying. Journal of Food Engineering, v.48, p.169-175, 2001.

Mbata, G. N.; Osuji, F. N. C. Some aspects of the biology of Plodia interpunctella (Hübner) (Lepidoptera: Pyralidae), a pest of stored groundnuts in Nigeria. Journal of Stored Products Research, v.19, n.3, p.141-151, 1983. 
Mclellan, M. R.; Lind, L. R.; Kime, R. W. Hue angle determinations and stastistical analysis for multiquadrant hunter L, a, b data. Journal of Food Quality, v.18, n.3, p.235-240, 1995.

Minguez-Mosquera, M. I.; Rejano-Navarro, L.; Gandul-Rojas, B.; Sanchez-Gómez, A. H., Garrido-Fernandez, J. Color-pigment correlation in virgin olive oil. Journal of the American Oil Chemists’ Society, v.72, n.12, p.1425-1429, 1995.

Molteberg, G. L.; Vogt, G.; Nilsson, A.; Frolich, W. Effects of storage and heat processing on the content and composition of free fatty acids in oats. Cereal Chemistry, v.72, n.1, p.88-93, 1995.

Muir, W. E.; White, N. D.G. Microorganisms in stored grain. In: Muir, W. E. (ed.) Manitoba: Grain Preservation Biosystems, 2000. p.1-17.

Narayan, R.; Chauhan, G. S.; Verma, N. S. Changes in the quality of soybean during storage. Part 1 - Effect of storage on some physicochemical properties of soybean. Food Chemistry, v.27, p.12-23, 1988.

Navarro, S.; Noyes, S. T. The mechanics and physics of modern grain aeration management. Boca Raton: CRC Press, 2001. 672p.

Rupollo, G.; Gutkoski, L.C.; Marini, L. J .; Elias, M. C. Sistemas de armazenamentos hermético e convencional na conservabilidade de grãos de aveia. Ciência Rural, v.34, n.6, p.1715-1722, 2004.
Tang, S.; Tekrony, D. M.; Egli, D. B.; Cornelius, P. L. Survival characteristics of corn seed during storage: II. Rate of seed deterioration. Crop Science, v.39, p.1400-1406, 1999.

Saio, K.; Nikkuni, I.; Ando, Y.; Osturu, M.; Terauchi, Y.; Kito, M. Soybean quality changes during model storage studies. Cereal Chemistry, v.57, p.77-82, 1980.

Sinclair, J. B. Discoloration of soybean seeds - an indicator of quality. Plant Disease, v.76, n.11, p.1087-1090, 1992.

Sinclair, J. B. Reevaluation of grading standards and discounts for fungus-damaged soybean seeds. Journal of the American Oil Chemists' Society, v.72, n.12, p.1415-1419, 1995.

Villa, L. G.; Roa, G. Secagem e armazenamento da soja industrial e sementes a granel. Campinas: Fundação Cargill, 1979. 64p.

Wilson, R. F.; Novitzky, W. P.; Fenner, G. P. Effect of fungal damage on seed composition and quality of soybeans. Journal of the American Oil Chemists' Society, v.72, n.12, p.1425-1429, 1995.

Zhou, Z.; Robards, K.; Helliwell, S.; Blanchard, C. Ageing of stored rice: changes in chemical and physical attributes. Journal of Cereal Science, v.35, p.65-78, 2002. 